\title{
www.czasopisma.pan.pl \\ Influence of the Hardener Type on the Hardening Process Kinetics of the Selected Self-setting Sands
}

\author{
L. Jamrozowicz *, J. Kolczyk **, N. Kaźnica, Z. Pyziak \\ AGH University of Science and Technology, Faculty of Foundry Engineering, \\ Reymonta 23, 30-059 Cracow, Poland \\ *Corresponding author. E-mail address:*1jamroz@agh.edu.pl,**kolczyk@agh.edu.pl
}

Received 30.06.2016; accepted in revised form 24.08.2016

\begin{abstract}
Measurements of the hardening process of the selected self-setting sands are presented in the hereby paper. Moulding sands were prepared on the matrix of „Szczakowa” sand of the Sibelco Company. Two resins: phenol-formaldehyde-furfuryl (FF/AF) and urea-formaldehydefurfuryl (MF/AF) were used for making moulding sands. - Methylbenzene-sulphonic acid was applied as a hardener for the moulding sand on $\mathrm{FF} / \mathrm{AF}$ resin, while paratoluene-sulphonic acid for the moulding sand on MF/AF resin. Both hardeners were used in two concentrations: low - the so-called 'slow' hardener and high - 'fast' hardener. During investigations, the courses of the hardening process were determined, more accurately changes of the velocity of the ultrasound wave passage through the moulding sand $c_{L}=f(t)$ and changes of the moulding sand hardening degree versus time, $S x=f(t)$. In addition, the kinetics of the hardening process was determined. Measurements were performed on the research stand for ultrasound investigations.
\end{abstract}

Keywords: Loose self-setting sands, Hardening kinetics, Ultrasound investigations

\section{Introduction}

Self-setting sands are moulding sands which are bonding (solidifying) at an ambient temperature. In addition, all components, i.e. sand, binder and hardener, are introduced - in an appropriate order - into the mixer. In dependence of the binder amount (percent fraction), self-setting sands can be divided into loose and liquid sands. Mainly loose sands are applied in industries. In dependence of the binder kind the self-setting sands can be divided into [1]:

- $\quad$ inorganic - the most often water glass is a binder,

- $\quad$ organic - the most often furfuryl and phenol-formaldehyde resins are applied as binders.
Popularity of loose self-setting sands results from their various advantages, such as $[1,13]$ :

- $\quad$ bonding at an ambient temperature,

- $\quad$ small amount of binder needed at these sands preparation,

- good fluidity,

- $\quad$ good knocking out property,

- $\quad$ satisfying dimensional accuracy of castings, which undoubtedly is their good point,

- $\quad$ possibility of producing resistant cores of complicated shapes, without the need of their dividing,

- $\quad$ reduction of efforts at moulds and cores production.

In turn, their negative features are as follows $[1,13]$ :

- relatively long time of bonding, 
- $\quad$ short working time,

- harmfulness for surroundings,

- relatively high costs.

The hardening process of moulding sands with binders starts in the moment of mixing, it means when all components, taking part in the hardening reaction, are in contact with each other.

Each chemical reaction occurs with the determined rate. The concentration change of the substrate or product of the reaction in the time unit is considered the reaction rate measure. It can be expressed by equation 1 or - more precisely - by equation $2[2,3]$ :

$\mathrm{v}= \pm \frac{\mathrm{dc}_{\mathrm{i}}}{\mathrm{dt}}$

or more detailed

$\mathrm{v}=-\frac{\mathrm{dc}_{\mathrm{s}}}{\mathrm{dt}}=+\frac{\mathrm{dc} \mathrm{p}}{\mathrm{dt}}$

where:

$v$ - szybkość reakcji

$c_{i}$ - reagent concentration, ,i",

$\mathrm{t}$ - time,

$\mathrm{c}_{\mathrm{s}}, \mathrm{c}_{\mathrm{p}}$ - concentration of substrate, product,

The reaction rate depends on the concentration of substances taking part in the reaction. This dependence can be expressed by the kinetic equation (3) $[2,3]$ :

$\mathrm{v}=\mathrm{k} * \mathrm{c}_{\mathrm{A}}^{\mathrm{a}} * \mathrm{c}_{\mathrm{B}}^{\mathrm{b}} * \mathrm{c}_{\mathrm{C}}^{\mathrm{c}}$

where:

$\mathrm{A}, \mathrm{B}, \mathrm{C}$ - reactants,

$\mathrm{c}_{\mathrm{A}}, \mathrm{c}_{\mathrm{B}}, \mathrm{c}_{\mathrm{C}}-$ molar concentration of these substances,

$\mathrm{a}, \mathrm{b}, \mathrm{c}-$ exponents called orders of reaction, and their sum:

$\mathrm{a}+\mathrm{b}+\mathrm{c}=\mathrm{n}-$ overall order of reaction,

$\mathrm{k}$ - reaction rate constant, characteristic for the given reaction regardless of concentrations, but significantly dependent on a temperature.

Chemical reactions, from the kinetics point of view, can be divided into homogeneous and heterogeneous. A homogeneous reaction occurs totally in one phase (liquid, gaseous), while heterogeneous reaction on the interphase boundary.

In heterogeneous reactions, important factors influencing their rates are diffusion processes: substrates towards a surface on which the reaction occurs and products in the opposite direction.

Figure 1 presents concentration changes of substrates and products in time.

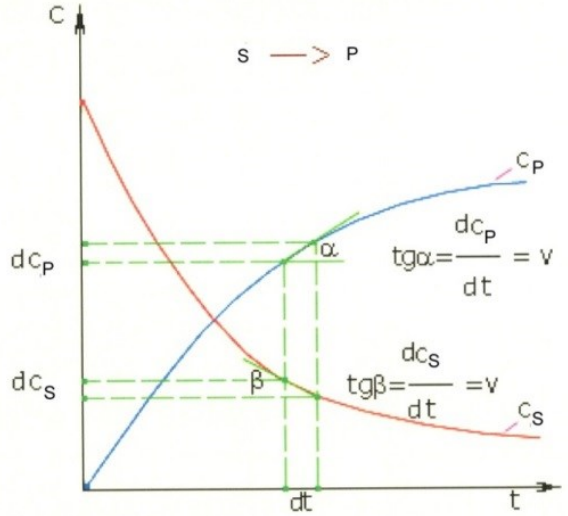

Fig. 1. Concentration changes of substrates and products as a time function [2]

A chemical reaction rate depends on [2 - 4]:

- reagents concentration,

- temperature,

- $\quad$ pressure (when reagents are gases),

- $\quad$ electromagnetic radiation (for photochemical reactions),

- development of surfaces (surface reactions),

- $\quad$ catalyst additions.

Some factors influence courses of every reaction - e.g. temperature, others have a limited range.

Understanding courses and kinetics of the hardening process of self-setting sands is very important from the research as well as utilitarian point of view. In the industrial practice, occurs a need of assessing such parameters as $[4,5]$ :

- $\quad$ self-setting sand strength properties,

- $\quad$ working time,

- $\quad$ time of a preliminary and complete hardening of self-setting sands,

- $\quad$ advancement degree of the hardening process.

When the time of preliminary hardening of the moulding sand in the mould is determined, it is possible to lift a pattern from the mould or a core from the core box, while after determining the time of complete hardening - a core can be deposited in the mould cavity and the mould poured with liquid metal $[4,6]$

During the hardening process, a moulding sand changes its rheological properties. Immediately after preparation it has viscoelastic properties, whereas during the process changes its rheological properties into elastic-plastic with decaying plasticity, and after hardening shows nonlinear-elastic properties. The rheological properties changes cause changes of the moulding sand ability for the ultrasound wave propagation. The more hardened is a moulding sand, (in other words: when the hardening degree increases, the wave damping coefficient decreases), the shorter is time of passing through the given moulding sand layer, (the ultrasound wave velocity is high). When considering the measurement methodology - it is obvious - that the wave velocity can be much easier and more accurately determined than its damping. Ultrasound testers of materials are adapted for 
measuring time of the ultrasound wave passing through the tested sample $[4,6,7,14]$.

The measurement of the ultrasound wave velocity in the mould or core allows to determine the hardening degree of all kinds of moulding sands, where the hardening process occurs by means of a chemical bonding of binder components, regardless of the hardening rate. Measurements of times of the ultrasound wave passage through the moulding sand allow to investigate the bonding process and the factors influencing it in non-destructive way. These investigations can be carried out under laboratory as well as industrial conditions. No other method allows for such wide spectrum of investigations and control of the hardening process, providing information concerning this process stability $[4,6,8-12]$.

Several factors influence the hardening process course and the wave velocity values $[4,6,11,15]$ :

- $\quad$ matrix (size, grains shapes),

- $\quad$ binder (kind and amount used for preparing a moulding sand),

- $\quad$ hardener (kind and amount used for preparing a moulding sand),

- $\quad$ hardening degree of a moulding sand.

That is why the real wave velocity in the tested sample of the hardened moulding sand can be only an indicator of the advancement degree of the bonding process. In addition, the relative velocity value i.e. a quotient of an instantaneous and initial value, does not contain the full information on an advancement degree of the hardening process $[4,6,8,15]$.

The coefficient, called the hardening degree $\mathrm{Sx}$, was developed for the assessment of the advancement degree of the moulding sand hardening process. This coefficient has also a technological aspect, since it informs in which hardening phase is the hardened moulding sand. Coefficient Sx determining the moulding sand hardening degree is defined by equation 4 , based on the dimensionless wave velocity [4]:

$S_{x}=\frac{c_{L(x)}-c_{L(0)}}{c_{L(\max )}-c_{L(0)}}$

where:

$\mathrm{Sx}$ - velocity-based hardening degree of a moulding sand, $\mathrm{c}_{\mathrm{L}(\mathrm{x})}$ - wave velocity in a sample determined in the given moment,

$\mathrm{c}_{\mathrm{L}(0)}$ - wave velocity in a sample in the initial moment, $(\mathrm{t}=0)$, $\mathrm{c}_{\mathrm{L}(\max )}$ - wave velocity in a sample after its complete hardening.

This coefficient is within the interval: $0.0-1.0$, or within the range: $0-100 \%$. Immediately after mixing of all moulding sand components both velocities, instantaneous and initial, are equal and thus the moulding sand hardening degree, $\mathrm{Sx}=0.0 \%$. However, when the bonding process is nearly at the end, it means when the measured increase of the wave velocity decays, and this velocity achieves its maximum value, the moulding sand hardening degree equals: $\mathrm{Sx}=1.0$ (or $100 \%$ ). The moulding sand achieves then its maximum strength $[4,9]$.

\section{Own investigations}

\subsection{Aim and methodology of investigations}

One of the factors deciding on the hardening process of loose self-setting moulding sands is the selection of the proper hardener (of an adequate concentration). The aim of the performed investigations was to determine the hardener influence on the course and kinetics of the hardening process.

Investigations were carried out on the research stand for ultrasound tests - Figure 2.

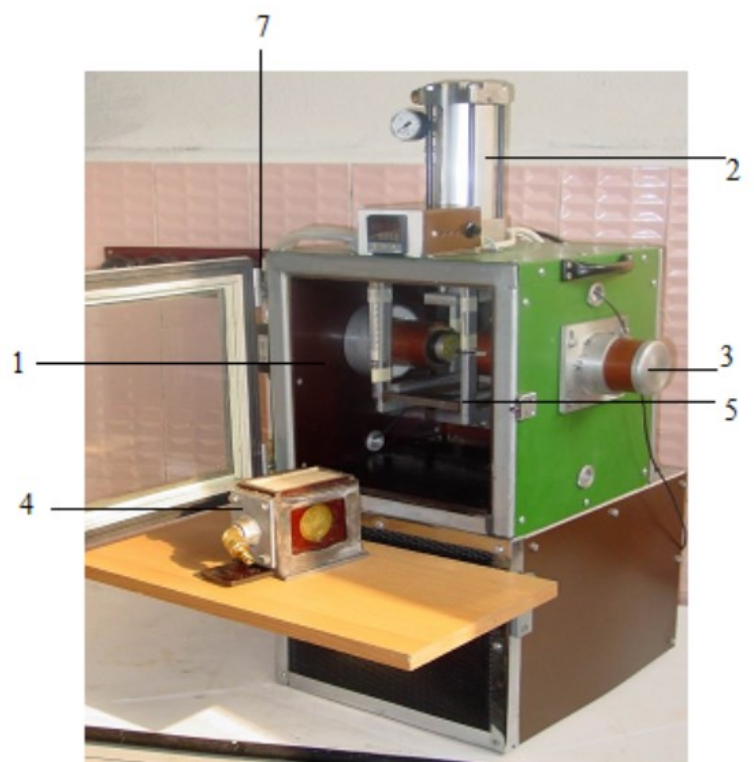

Fig. 2. Research stand, for investigating the hardening kinetics of moulding sands with chemical binders, together with the chamber stabilising a temperature $[4,6,14]-1$ - air conditioned measuring chamber; 2- pneumatic servo-motor; 3-ultrasound heads; 4sample of the tested moulding sand; 5- suspended table with an open bottom; 6- control valve of a servo-motor; 7- filteringreducing system with a manometer

\subsection{Kinds of performed investigations}

High-silica sand Sibelco BK4 „Szczakowa” of a main fraction FG 0.40/0.32/0.20 was used as a moulding sand matrix. Two resins in amounts: 1.5 parts by weight for 100 parts of sand were used for preparing moulding sands:

- $\quad$ resin 1 - phenol-formaldehyde-furfuryl

- $\quad$ resin 2 - urea-formaldehyde-furfuryl

For each resin two hardeners were selected and applied:

for resin 1 :

- hardener 11 'slow' - methylbenzenesulphonic acid of a low concentration 
- hardener 12 'fast' - methylbenzenesulphonic acid of a high concentration

for resin 2:

- hardener 21 'slow' - solution of paratoluenesulphonic acid of a low concentration

- $\quad$ hardener 22 'fast' - solution of paratoluenesulphonic acid of a high concentration

Courses of wave velocity $c_{L}=f(t)$, hardening degrees $S x=f(t)$ and the kinetics of this process $\mathrm{dSx} / \mathrm{dt}=\mathrm{f}(\mathrm{t})$ were determined during investigations. Investigations were performed at a constant ambient temperature being $20^{\circ} \mathrm{C}$.

\subsection{Courses of the hardening process}

Figure 3 presents the course of wave velocity changes during the hardening process of moulding sand based on resin 1 , hardened by two hardeners, marked as hardener 11 'slow' and hardener 12 'fast'. Both courses of the moulding sands hardening are of a similar character. They can be divided into two periods differing in the intensity of the ultrasound wave velocity increase in time. In the first period this hardening process is very fast, causing very intensive changes of the ultrasound wave velocity. When the 'slow' hardener was applied the intensity of wave velocity increase was lower than when the 'fast' hardener was applied. For the 'fast' hardener the wave velocity increases from $350[\mathrm{~m} / \mathrm{s}]$ to $1400[\mathrm{~m} / \mathrm{s}]$ in 60 minutes, while for the moulding sand with the 'slow' hardener the wave velocity achieves 1400 $[\mathrm{m} / \mathrm{s}]$ after nearly 240 minutes. In the second period the hardening process slows down, and thus wave velocity changes are not so intensive. After 24 hours of testing the moulding sand hardening process the $C_{L}$ value, in case of the moulding sand with the 'slow' hardener, equals app. $1650[\mathrm{~m} / \mathrm{s}]$, while in case of the moulding sand with the 'fast' hardener the $C_{L}$ value equals app. $1800[\mathrm{~m} / \mathrm{s}]$. The higher final value of the wave velocity of the sand with the 'fast' hardener probably means the higher moulding sand strength. A continuous increase of the curves in the diagram indicates that the hardening process was not finished for both hardeners.

In turn, Figure 4 presents a comparison of changes in the hardening degree for the moulding sand based on resin 1 with the 'slow' and 'fast' hardeners. Analysing the courses of changes of the hardening degree $\mathrm{Sx}$, it is possible to determine the time after which the pattern can be taken out from the mould as well as it is possible to predict the time after which the mould can be poured. When the hardening degree Sx will reach $75-80 \%$, a moulding sand has high enough strength that taking out the pattern from the mould will not cause any damage of the mould cavity. A moulding sand with a 'slow' hardener reaches the hardening degree $\mathrm{Sx}=80 \%$ after $\mathrm{t}=120$ minutes, while a moulding sand with a 'fast' hardener after twice longer time, $t=240$ minutes. The second technological parameter, which can be determined on the basis of the hardening degree, is the time after which the mould is ready to be poured, it means the time after which Sx equals at least $90 \%$.

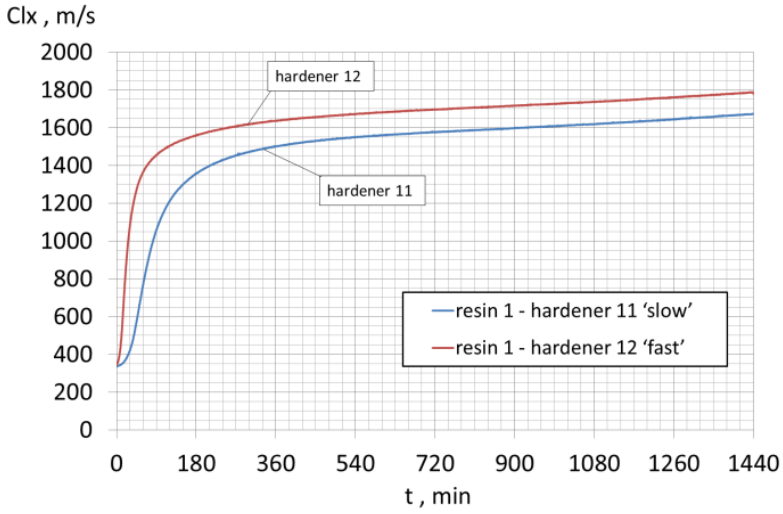

Fig. 3. Influence of the hardener type on the wave velocity changes. Matrix - high-silica sand BK4, binder - resin 1, investigations performed at a temperature of $20^{\circ} \mathrm{C}$

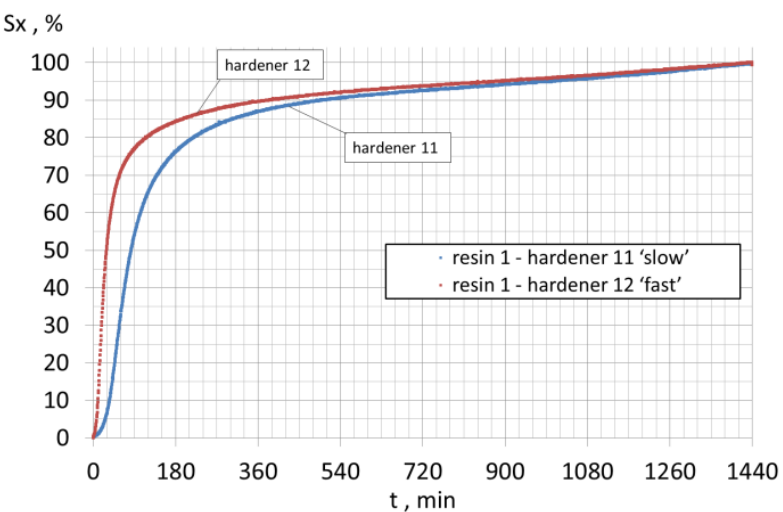

Fig. 4. Influence of the hardener type on the changes of the hardening degree Sx. Matrix - high-silica sand BK4, binder resin 1 , investigations performed at a temperature of $20^{\circ} \mathrm{C}$

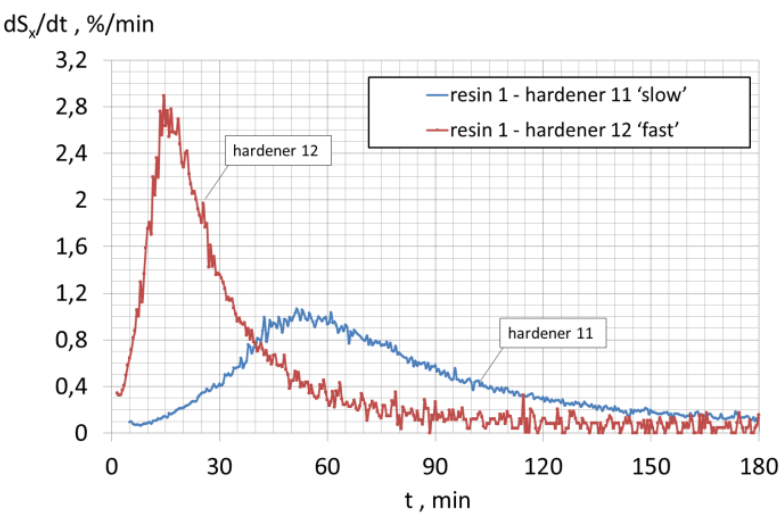

Fig. 5. Influence of the hardener type on the kinetics of the moulding sand hardening process. Matrix - high-silica sand BK4, binder - resin 1 , investigations performed at a temperature of $20^{\circ} \mathrm{C}$

The kinetics of the moulding sand hardening process, it means the changes of the hardening degree versus time are presented in Figure 5. The hardening process is less intensive when the 'slow' hardener is applied, than when the 'fast' one is applied. It is 
indicated by the maximum $\mathrm{dSx} / \mathrm{dt}$ value equaled $1[\% / \mathrm{min}]$ for the 'slow' hardener, and over $2.8[\% / \mathrm{min}]$ for the 'fast' hardener. What's more, times after which $\mathrm{dSx} / \mathrm{dt}$ achieves its maximum values are different for individual moulding sands - for the sand with the 'slow' hardener it is $50 \mathrm{~min}$, while for the sand with the 'fast' hardener only 15 minutes. It is assumed that this time determines the moulding sand working time.

Identical investigations were performed for the moulding sand with resin 2 and analogous courses as for the moulding sand with resin 1 were determined, it means changes of the wave velocity (Fig. 6), hardening degree (Fig.7) and kinetics of hardening (Fig. 8) in time.

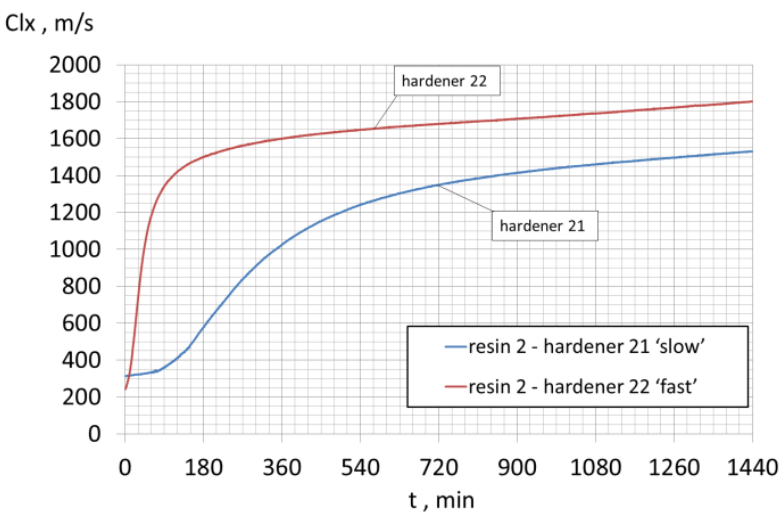

Fig. 6 . Influence of the hardener type on the wave velocity changes. Matrix - high-silica sand BK4, binder - resin 2, investigations performed at a temperature of $20^{\circ} \mathrm{C}$

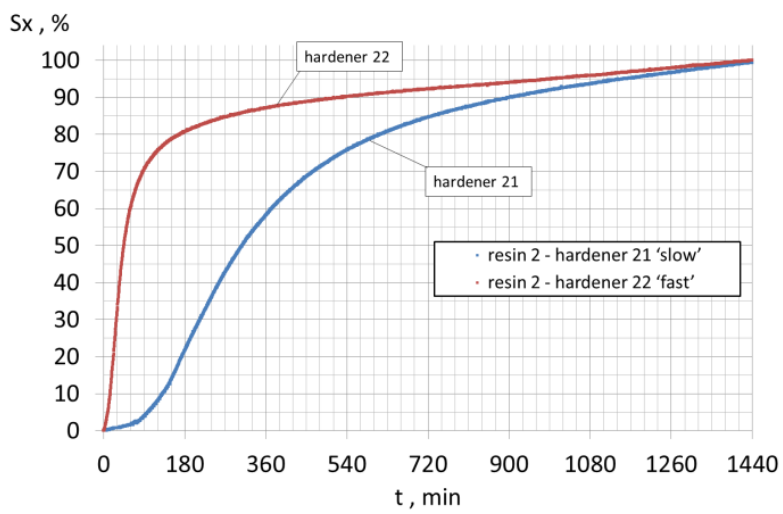

Fig. 7. Influence of the hardener type on the changes of the hardening degree Sx. Matrix - high-silica sand BK4, binder resin 2 , investigations performed at a temperature of $20^{\circ} \mathrm{C}$

When analysing the diagrams of wave velocity changes in time shown in Figure 6, a significant difference in the courses between the moulding sand with the 'slow' hardener and with the 'fast' one, can be noticed. The wave velocity change for moulding sand with the 'fast' hardener is intensive and achieves a value of $1400[\mathrm{~m} / \mathrm{s}]$ in app. 120 minutes, while in case of the 'slow' hardener the character of wave velocity changes is soft and a value of $1400[\mathrm{~m} / \mathrm{s}]$ is achieved after barely 14 hours. After 24 hours from the moulding sand preparation the $C_{L}$ value for the sand with the 'fast' hardener equals app. $1800[\mathrm{~m} / \mathrm{s}]$, while for the sand with the 'slow' hardener app. $1550[\mathrm{~m} / \mathrm{s}]$. The higher wave velocity the more hardened moulding sand, i.e. of a higher strength. In relation to this, it can be stated that the moulding sand with the 'slow' hardener will have less strength than the sand with the 'fast' hardener. The analysis of curves indicates additionally that the hardening process was not finished in both cases.

Figure 7 presents a comparison of hardening degree changes of the moulding sand with resin 2 and the 'slow' and 'fast' hardener. Utilising the dependence that the moulding sand hardening degree Sx being $75-80 \%$ allows to remove the pattern from the mould without its damaging (on the bases of a sufficiently high strength of a moulding sand), the attention should be directed towards time, after which the tested moulding sands achieve the mentioned above hardening degree Sx. The sand with the 'fast' hardener achieves $\mathrm{Sx}=80 \%$ in $\mathrm{t}=150$ minutes, while the sand with the 'slow' hardener in $t=600$ minutes. Such long time (600 minutes) necessary for the preliminary hardening of the moulding sand is disadvantageous under industrial conditions. The pattern would be used for making only one mould during one work-shift, which would significantly decrease the work efficiency in a foundry. A long bonding time is the reason that the moulding sand with resin 2 and the 'slow' hardener should not be used in a foundry when the preparation, formation and bonding stages of this sand are carried out at a temperature of app. $20^{\circ} \mathrm{C}$.

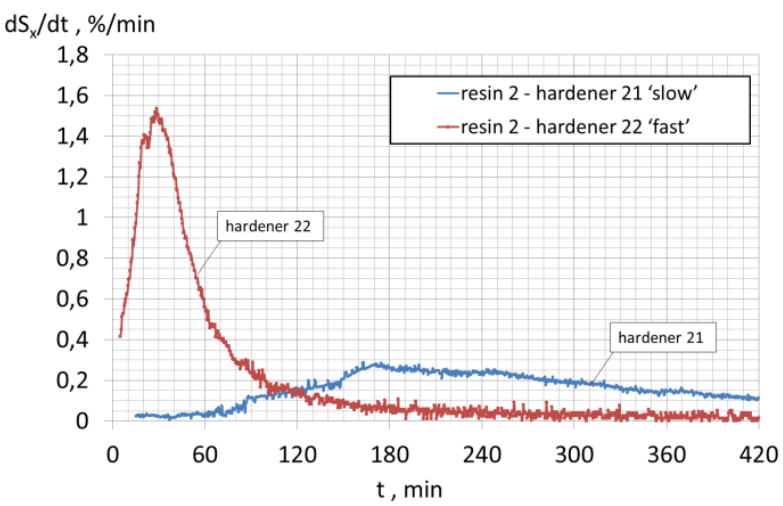

Fig. 8. Influence of the hardener type on the kinetics of the moulding sand hardening process. Matrix - high-silica sand BK4, binder - resin 2 , investigations performed at a temperature of $20^{\circ} \mathrm{C}$

The kinetics of the moulding sand hardening process, i.e. the hardening degree rate changes versus time are presented in Figure 8 . The maximum value of $\mathrm{dSx} / \mathrm{dt}$ equals only $0.3[\% / \mathrm{min}]$ for the moulding sand with the 'slow' hardener, while for this sand with the 'fast' hardener $\mathrm{dSx} / \mathrm{dt}$ equals more than $1.5[\% / \mathrm{min}]$. The small $\mathrm{dSx} / \mathrm{dt}$ value is a result of a long working time being nearly 180 minutes. For the moulding sand with the 'fast' hardener the working time is 4 times shorter (30 minutes).

\section{Conclusions}

On the basis of the performed investigations several conclusions - shown below - can be formulated. 
- The application of the ultrasound method provides the possibility of the continuous monitoring of the moulding sand bonding process.

- Determination of the wave velocity courses $\mathrm{Clx}=\mathrm{f}(\mathrm{t})$, hardening degree $\mathrm{Sx}=\mathrm{f}(\mathrm{t})$ and process kinetics $\mathrm{dSx} / \mathrm{dt}=$ $\mathrm{f}(\mathrm{t})$, allows to determine - in a simple way - the most important technological parameters of the moulding sand, it means: working time, preliminary bonding time, and the time after which the mould can be poured with liquid metal.

- In case of the moulding sand with resin 1 applying the 'slow' hardener increases the moulding sand working time to 50 minutes, while for the 'fast' hardener this was only 15 minutes. However, the application of the 'slow' hardener has also disadvantageous effect, which is the prolongation of the preliminary bonding time from 120 minutes ('fast' hardener) to 240 minutes ('slow' hardener).

- The 'slow' hardener is not suitable for hardening of moulding sand with resin 2 , when the bonding process is carried out at an ambient temperature being $20^{\circ} \mathrm{C}$. The preliminary bonding time equals app. 600 minutes, which makes impossible the effective usage of patterns.

- At the ambient temperature, being $20^{\circ} \mathrm{C}$, the hardener selection depends on the resin kind and technological parameters of a moulding sand: working time or preliminary hardening time.

\section{Acknowledgements}

The research was performed within the project PBS3/B5/47/2015

\section{References}

[1] Lewandowski, J.L. (1997). Materials for molds. Kraków: Wydawnictwo Akapit. (in Polish).

[2] Staronka, A. (1994). Physical chemistry. Kraków: Wydawnictwa AGH. (in Polish).

[3] Zych, J. (2002). The setting kinetic of moulding sands with water glass. Acta Metallurgica Slovaca. 8(2), 93-98.

[4] Zych, J. (2007). Synthesis uses ultrasonic technique in the analysis of the kinetics of selected processes in the plastics molding. Kraków: Uczelniane Wydawnictwa Naukowo-
Dydaktyczne. Seria: Rozprawy i Monografie nr 163. (in Polish)

[5] Zych, J. (2001). The influence of temperature on the setting kinetics of moulding sands with chemical binders. Archives of Mechanical Technology and Automation. 21(1), 161-169.

[6] Zych, J. (2002). The new non-destructive method of the control of the quality of the elements of forms executed from moulding sand with chemical binder. Archives of Foundry. 3(5), 132-139. (in Polish).

[7] Deputat, J. (1996). New techniques of ultrasonic testing of materials. Solidification of Metals and Alloys. 26, 101-110. (in Polish).

[8] Zych, J. (2007). Das Verhalten chemisch gebundener Formstoffe unter wechselnden Umgebungsbedingungen [Behaviour of moulding sand with chemical binders in changeable weathers conditions]. Giessereipraxis. 58(1-2), 22-28.

[9] Dańko, J. \& Zych, J. (2002). Non-destructive test method for assessing uniformity cores compacting and determining the distribution strength and permeability. Archives of Foundry. 3(5), 132-139. (in Polish).

[10] Jamrozowicz, Ł. \& Zych, J. (2010). The moulds and cores made of fast setting moulding sands - determination of speed rate of front hardening transfer. Archives of Foundry Engineering. 10(spec.2), 173-176. (in Polish).

[11] Jamrozowicz, Ł. \& Zych, J. (2010). Advancement of the hardening front in forms and cores made of quickly bonding composites - ultrasonic analyses. Archives of Metallurgy and Materials. 55(3), 963-968.

[12] Jamrozowicz, Ł. \& Zych, J. (2011). The change of the gas pressure in cores made in cold-box technology during their hardening. Archives of Foundry Engineering. 11(4), 204208.

[13] Bieda, S. (2006). Manufacture of molds and cores using furan resins cold cure manual Hüttenes-Albertus. Przeglad Odlewnictwa. 7-8, 324-329. (in Polish).

[14] Zych, J. (2003). Novo método ultra-sonico de monitoração do processo de cura - [The novel ultrasonic mothod of monitoring the setting process of moulding sands with chemical binders]. Fundição e Serviços. 14(128), 146-156.

[15] Zych, J. (2000). Prüfen von kunstharz- und wasserglasgebundenen Formsanden mit der Ultraschallmethode [Ultrasonic testing of moulding sands with resins and waterglass]. Giesserei-Erfahrungsaustausch. 4, 193-196. 